\title{
Nuevas fórmulas docentes para la didáctica de "Protección de cultivos": contenidos y formas
}

\author{
Alicia LORENZANA DE LA VARGA \\ Universidad de León \\ alorv@unileon.es
}

\begin{abstract}
Resumen:
Sobre la base legal relativa a la adaptación de los estudios españoles al EEES, la asignatura "Protección de cultivos" se incluye en los Planes de Estudio que conducen a los grados de Ingeniería Agraria y del Medio Rural, Ingeniería Agroambiental e Ingeniería Agroalimentaria de la Universidad de León. El objetivo de este trabajo es proponer una estrategia docente basada en sistema de aprendizaje-mezclado (B-learning). La implantación de esta propuesta permite probablemente reforzar el aprendizaje independiente y hacer más fácil la adquisición de las habilidades necesarias para el estudiante.
\end{abstract}

Palabras clave: Protección de cultivos; B-learning; TIC; Moodle; EEES

New teaching formulas of "Crop protection" didactic: contents and forms.

\begin{abstract}
:
On the basis of legal framework about the Spanish studies adaptation to the EHEA, the course "Crop protection" is in the syllibuses of the degrees of "Agricultural and Rural Environmental Engineering", "Agro-Environmental Engineering" and "Agrifood Engineering" of the University of León. This paper is intended to propose a new teaching strategy based on blended system teaching-learning (B-learning). The effects of implementing this proposal are likely to strengthen independent learning and make it easier to acquire the necessary abilities that students must achieve.
\end{abstract}

Key Words: Crop protection; B-learning; ICT; Moodle; EHEA

Referencia normalizada:

Lorenzana de la Varga, A. (2014): Nuevas fórmulas docentes para la didáctica de "Protección de cultivos": contenidos y formas. Historia y Comunicación Social. Vol. 19. Núm. Especial Febrero. Págs. 707-718.

Sumario: 1. Introducción. 2. Metodología. 2.1. Materiales y actividades formativas. 2.2. Descripción detallada del programa. 3. Resultados. 4. Conclusiones. 5. Referencias bibliográficas.

\section{Introducción}

Cumpliendo la normativa legal relativa a la adaptación de los estudios españoles al Espacio Europeo de Educación Superior (EEES), definida en el Real Decreto 1393/2007 (BOE, 2007: 44037), en el curso 2010-11 se incluye la asignatura "Protec- 
ción de Cultivos" en los planes de estudio que conducen al Grado en Ingeniería Agraria y del Medio Rural, Grado en Ingeniería Agroambiental y Grado en Ingeniería Agroalimentaria de la Universidad de León. Según se recoge en sus memorias (Universidad de León, 2009), el primero permite la adquisición de competencias de los módulos de tecnología específica de Explotaciones Agropecuarias y Mecanización y Construcciones Rurales, el segundo las de Hortofruticultura y Jardinería, y el tercero las de Industrias Agrarias y Alimentarias, definidas en la Orden CIN/323/2009 (BOE, 2009: 17719). La asignatura de "Protección de cultivos" permitirá obtener la competencia "capacidad para conocer, comprender y utilizar los sistemas de protección vegetal". Se trata de una asignatura con una carga lectiva de 6 créditos ECTS (European Credit Transfer System) que se imparte en el tercer curso de los tres grados.

El objetivo del presente trabajo es promover una estrategia docente para dicha asignatura que promueva el aprendizaje significativo. Combinando una serie de actividades formativas el alumno deberá conocer y comprender los principios básicos de la biología y desarrollo de los organismos perjudiciales y beneficiosos de los cultivos agrícolas, ser capaz de identificarlos, evaluar su densidad, evolución y el riesgo derivado de su presencia. Además, deberá adquirir la capacidad de proponer métodos para su prevención y control en el marco de la producción vegetal sostenible, así como buscar e interpretar datos relevantes para apoyar la toma de decisiones y transmitir información en materia de sanidad vegetal.

\section{Metodología}

2.1. Materiales y actividades formativas

La asignatura dispone de los siguientes recursos: (i) humanos -profesorado del Departamento de Ingeniería y Ciencias Agrarias de la Universidad de León (ULE)-, (ii) estructurales -instalaciones de la E.S.T.I.A. y espacios comunes de la ULE: Biblioteca Central, Centro de Tecnologías de la Información y las Comunicaciones (TIC)- y (iii) materiales -material impreso, pizarra, medios audiovisuales y TIC, fundamentalmente a través del aula virtual en el entorno Moodle (Modular Object-Oriented Dynamic Learning Environment)-.

Por otro lado, durante el desarrollo de las actividades proyectadas se pone en contacto al alumno, de forma directa o indirecta con 9 libros básicos, 485 libros complementarios, 127 publicaciones periódicas, 60 bases de datos, 118 enlaces web, 13 actas de congresos, 42 vídeos y diferentes CD-Rom, programas informáticos y colecciones de transparencias y diapositivas.

Las actividades formativas propuestas para la asignatura son:

- Clases teóricas: no se considera conveniente acabar con la práctica de la lección magistral, si bien se considera necesario complementarla con otras 
dinámicas pedagógicas más participativas y abiertas. Los temas se expondrán mediante la clase magistral participativa con apoyo de presentaciones y conexiones a enlaces web, facilitando previamente el texto a través de la plataforma de campus virtual. Se calculan 2 horas de estudio no presencial del alumno por cada hora presencial.

- Prácticas de laboratorio: se consideran imprescindibles para consolidar los conceptos y métodos expuestos en las clases teóricas, siendo además fundamentales para conseguir las competencias en el campo afectivo (actitudes) y psicomotor (habilidades). Se dedicará a cada práctica unos 30 minutos, contando el alumno además con 4 horas para acudir por su cuenta al laboratorio.

- Prácticas de campo: son fundamentales para poner en contacto al alumno con la realidad profesional. Se proponen dos prácticas de campo (Estación de Avisos Agrícolas del Bierzo de la Junta de Castilla y León, Carracedelo (León) y visita al campo de prácticas de la E.S.T. de Ingeniería Agraria de la ULE y a explotaciones cercanas con cultivos de interés).

- Lecturas y búsquedas de información: se realizarán a través de internet (e-learning) para que el alumno construya conocimientos de forma significativa y responsable, si bien también se utilizarán libros, revistas, catálogos y otros.

- Seminarios: se incluyen dentro de las técnicas activas de participación del alumno en la enseñanza, fomentando el diálogo entre alumnos y profesor y entre alumnos entre sí. Se realizarán por grupos de 2 a 4 alumnos y cada uno llevará un tiempo de unos 20 a 30 minutos.

- Debates dirigidos: permiten que los participantes expresen sus opiniones de forma libre, y enseñan a tolerar otras ideas diferentes a las suyas. El alumno dispondrá del tiempo necesario para la lectura de la información, dedicándose posteriormente a cada debate unos 30 minutos.

- Tutorías: se centran en el alumno, al que se le permite establecer así una relación directa e individualizada con el profesor. Las tutorías presenciales serán individualizadas y las no presenciales (correo electrónico y plataforma de campus virtual) podrán ser individualizadas o en grupo.

\subsection{Descripción detallada del programa}

Se propone la división de la asignatura en tres unidades didácticas: (i) Zoología Agrícola: Entomología, (ii) Patología Vegetal y (iii) Control de plagas y enfermedades. A continuación se presenta la distribución temática con una breve descripción de los contenidos y las actividades propuestas en cada tema.

Bloque I: Zoología Agrícola: Entomología.

Tema 1.- Introducción a la Entomología Agrícola: Definición de Entomología agrícola. Etiología de las plagas. Sintomatología de las plagas. Medidas de lucha contra 
las plagas. Posición sistemática y caracteres generales de los artrópodos: Miriápodos, Insectos, Arácnidos y Crustáceos. Factores que contribuyen al éxito evolutivo de los insectos.

Actividad a desarrollar: Lectura: se recomendará al alumno la lectura de diversa bibliografía general sobre Entomología Agrícola.

Tema 2.- Organización general externa del cuerpo de los insectos: Organización general del cuerpo. Cabeza: organización general, piezas bucales y órganos sensoriales. Tórax: organización general, alas y patas. Abdomen: organización general y genitalia externa.

Actividad a desarrollar: Prácticas de laboratorio (Práctica 1): se observarán los caracteres morfológicos de los insectos utilizados para su identificación.

Tema 3.- Organización general interna y fisiología de los insectos: Tegumento. Sistema digestivo. Sistema respiratorio. Sistema excretor. Sistema sensorial y nervioso. Sistema reproductor. Sistemas endocrino y exocrino.

Actividad a desarrollar: Lectura: se propondrá a los alumnos la lectura y síntesis de la fisiología de distintos insectos.

Tema 4.- Reproducción y desarrollo de los insectos: Tipos de reproducción. Ventajas e inconvenientes de los tipos de reproducción. El proceso de muda. La metamorfosis. Desarrollos holometábolo y heterometábolo; estados inmaduros. Control hormonal de la muda. Quiescencia y diapausa.

Actividad a desarrollar: Búsqueda de información: se propondrá la búsqueda de información y síntesis del tipo de desarrollo de diferentes insectos.

Tema 5.- Sistemática de los insectos: Clasificación general de los insectos. Insecta Exopterygota: generalidades; Orden Orthoptera; Orden Thysanotera; Orden Hemiptera. Insecta Endopterygota: generalidades; Orden Coleoptera; Orden Lepidoptera; Orden Diptera; Orden Hymenoptera; Insectos beneficiosos.

Actividad a desarrollar: Búsqueda de información: se propondrá la búsqueda complementaria de fotografías de los distintos órdenes de insectos para que el alumno comience a familiarizarse con ellos.

Tema 6.- Orden Orthopthera: Características morfológicas y biológicas. Grupos de interés agrícola: Suborden Ensifera: Familia Gryllotalpidae; Suborden Caelifera: Familia Acrididae (langostas); Otros.

Actividad a desarrollar: Prácticas de laboratorio (Práctica 2): se identificarán las principales plagas pertenecientes al orden Orthopthera. Lectura: se propondrá la lectura y síntesis del "Plan de control e intervención contra la plaga de la langosta" disponible en la Web de la Junta de Castilla y León. Búsqueda de información: se propondrá la búsqueda de información y síntesis de la situación de la plaga de la langosta en el mundo en la página Web de la FAO. 
Tema 7.- Orden Thysanoptera: Características morfológicas y biológicas. Grupos de interés agrícola: Suborden Terebrantia: Familias Thripidae y Aeolothripidae; Suborden Tubulifera: Familia Phlaeothripidae.

Actividad a desarrollar: Prácticas de laboratorio (Práctica 3) se identificarán las principales plagas pertenecientes al orden Thysanopthera. Búsqueda de información: se propondrá la búsqueda del árbol taxonómico del orden Thysanopthera en la página Web Fauna Europaea.

Tema 8.- Orden Hemiptera: Características morfológicas y biológicas. Grupos de interés agrícola: Suborden Heteroptera: Familias Pentatomidae, Tingidae y Anthocoridae; Suborden Sternorrhyncha: Familias Aphididae, Psyllidae, Aleyrodidae y Superfamilia Coccoidea: Familias Coccidae, Pseudococcidae, Margarodidae y Diaspididae.

Actividad a desarrollar: Prácticas de laboratorio (Práctica 4): se identificarán las principales plagas pertenecientes al orden Hemiptera. Lectura: se propondrá la lectura y síntesis del Capítulo "Morfología y biología de los pulgones" de Barbagallo et al. (1998: 11) y del Capítulo "Características generales de las moscas blancas" de Llorens y Garrido (1992: 17). Búsqueda de información: se propondrá la búsqueda del árbol taxonómico del orden Hemiptera en la página Web Fauna Europaea. Debate: se propondrá la lectura y análisis de un artículo actual sobre un insecto perteneciente al orden Hemiptera. Dicho artículo procederá de una revista científica, de las actas de un congreso o reunión científica, de la Web de la Asociación Española de Entomología (AeE) o de la Web de la Sociedad Española de Entomología Aplicada (SEEA).

Tema 9.- Orden Lepidoptera: Características morfológicas y biológicas. Grupos de interés agrícola: Familias Noctuidae, Tortricidae y otras.

Actividad a desarrollar: Prácticas de laboratorio (Práctica 5): se identificarán las principales plagas pertenecientes al orden Lepidoptera. Búsqueda de información: se propondrá la recopilación de datos sobre curvas de vuelo de Cydia pomonella en diversas regiones frutícolas españolas. Dicha información está disponible en las páginas Web de las estaciones de avisos agrícolas de las distintas comunidades autónomas. Debate: se propondrá la lectura y análisis de un artículo actual sobre un insecto perteneciente al orden Lepidoptera, con las mismas fuentes que en el tema 8.

Tema 10.- Orden Coleoptera: Características morfológicas y biológicas. Grupos de interés agrícola: Familias Chrysomelidae: Subfamilias Bruchinae y Chrysomelinae, Cerambicidae, Elateridae, Melolonthidae, Dryophthoridae, Buprestidae, Curculionidae: Subfamilias Scolytinae y Curculioninae, y Coccinelidae.

Actividad a desarrollar: Prácticas de laboratorio (Práctica 6): se identificarán las principales plagas pertenecientes al orden Coleoptera. Búsqueda de información: se propondrá la búsqueda del árbol taxonómico del orden Coleoptera en la página Web Fauna Europaea, incidiendo especialmente en los insectos incluidos en la superfamilia Curculionoidea, afectada por cambios en su clasificación taxonómica. Debate: se 
propondrá la lectura y análisis de un artículo actual sobre un insecto perteneciente al orden Coleoptera, con las mismas fuentes que en el tema 8.

Tema 11.- Orden Diptera: Características morfológicas y biológicas. Grupos de interés agrícola: Familias Tephritidae, Agromyzidae, Cecidomyiidae, Anthomyiidae, Tipulidae y Syrphidae.

Actividad a desarrollar: Prácticas de laboratorio (Práctica 7): se identificarán las principales plagas pertenecientes al orden Diptera. Búsqueda de información: se propondrá la búsqueda de información y síntesis sobre la situación actual de la mosca de la fruta (Ceratitis capitata) en el Departamento de Agricultura, Alimentación y Acción Rural de la Generalitat de Cataluña.

Tema 12.- Orden Hymenoptera: Características morfológicas y biológicas. Grupos de interés agrícola: Suborden Symphyta: Familias Cephidae y Tenthredinidae; Suborden Apocrita: Familias Cynipidae e Ichneumonidae.

Actividad a desarrollar: Prácticas de laboratorio (Práctica 8) se identificarán las principales plagas pertenecientes al orden Hymenoptera. Búsqueda de información: se propondrá la búsqueda de información y síntesis de las características de distintas especies de parasitoides.

Tema 13.- Orden Neuroptera: Características morfológicas y biológicas. Grupos de interés agrícola: Familia Chrysopidae: especies depredadoras.

Actividad a desarrollar: Prácticas de laboratorio (Práctica 9) se identificarán las principales plagas pertenecientes al orden Neuroptera. Lectura: se propondrá la lectura y síntesis de diferentes fichas técnicas de neurópteros depredadores, las cuales están disponibles en las páginas Web de empresas dedicadas a la distribución y venta de organismos de control biológico.

Tema 14.- Ácaros: Posición sistemática y caracteres generales. Organización general externa e interna. Biología, reproducción y ciclos de desarrollo. Síntomas y daños sobre plantas cultivadas. Principales taxones: Ácaros fitófagos: Familias Tetranychidae y Eriophyidae; Ácaros depredadores: Familia Phytoseiidae y Otros.

Actividad a desarrollar: Debate: se propondrá la lectura y análisis de un artículo actual sobre un ácaro de interés agrícola, con las mismas fuentes que en el tema 8.

Tema 15.- Otros grupos zoológicos de interés agrícola: Miriápodos. Crustáceos. Moluscos: caracoles y babosas. Aves: gorrión, estornino y córvidos (grajas y cornejas). Mamíferos: insectívoros (topos) y roedores (ratas, ratones y topillos). Síntomas $\mathrm{y}$ daños que provocan sobre plantas cultivadas.

Actividad a desarrollar: Lectura: se propondrá la lectura y síntesis del "Plan de detección y control de las plagas de roedores" disponible en la Web de la Junta de Castilla y León

Tema 16.- Ecología y dinámica de poblaciones: Ecología y dinámica de poblaciones: Conceptos de agroecosistema, población y comunidad. Distribución espacial. 
Relaciones fitófago-medio agrícola. Dinámica de poblaciones. Muestreo. Factores reguladores de las poblaciones.

Actividad a desarrollar: Debate: se propondrá la lectura y análisis de un artículo actual sobre la dinámica poblacional de un insecto. Dicho artículo procederá de una revista científica o de las actas de un congreso o reunión científica relacionados con este tema.

\section{Bloque II: Patología Vegetal.}

Tema 17.- Introducción a la Patología Vegetal: Definición de Fitopatología y enfermedad. Clasificación de las enfermedades vegetales. Funciones básicas de las plantas e interferencias de las enfermedades. Diagnosis de enfermedades. Postulados de Koch. Ciclo de la enfermedad: Triángulo de las enfermedades; Etapas: Inoculación, penetración, infección, diseminación, invernación y estivación; Clasificación de los patógenos según su ciclo.

Actividad a desarrollar: Prácticas de laboratorio (Práctica 10): se enseñará la estructura y funcionamiento de un laboratorio de Patología Vegetal. Lectura: se recomendará al alumno la lectura de diversa bibliografía general sobre Patología Vegetal.

Tema 18.- Interacción planta-patógeno: Mecanismos de ataque. Efectos de los patógenos sobre la fisiología de las plantas. Mecanismos de defensa. Resistencia de las plantas.

Actividad a desarrollar: Lectura: se recomendará al alumno la lectura de la bibliografía complementaria.

Tema 19.- Agentes patógenos: hongos: Definición. Forma vegetativa de los hongos. Reproducción de los hongos. Clasificación general de los hongos. Clasificación de las micosis vegetales según la sintomatología característica: mildius, oídios, royas, carbones, micosis foliares, chancros, marchiteces vasculares, podredumbres radiculares y muerte de plántulas, podredumbre de frutos.

Actividad a desarrollar: Prácticas de laboratorio (Práctica 11): se reconocerán los síntomas originados por las principales micosis vegetales y sus estructuras fúngicas. Búsqueda de información: se propondrá la búsqueda de información y síntesis sobre diferentes micosis en la página Web de la American Phytopathological Society Debate: se propondrá la lectura y análisis de un artículo actual sobre un hongo fitopatógeno de interés. Dicho artículo procederá de una revista científica, de las actas de un congreso o reunión científica o de la Web de la Sociedad Española de Fitopatología (SEF).

Tema 20.- Agentes patógenos: procariontes: Definición. Principales características de los géneros de bacterias fitopatógenas. Clasificación de las bacteriosis vegetales según la sintomatología característica: manchas bacterianas, marchitamientos vasculares, pudriciones blandas, agallas bacterianas, chancros bacterianos, sarna bacteriana. Espiroplasmas y fitoplasmas. 
Actividad a desarrollar: Prácticas de laboratorio (Práctica 12): se reconocerán los síntomas originados por las principales bacteriosis vegetales y se observará el aspecto típico de sus colonias. Lectura: se propondrá la lectura y síntesis del "Plan de Contingencia del Fuego Bacteriano" disponible en la Web de la Junta de Castilla y León. Debate: se propondrá la lectura y análisis de un artículo actual sobre una bacteria fitopatógena de interés, con las mismas fuentes que en el tema 19.

Tema 21.- Agentes patógenos: virus: Definición. Transmisión de virosis vegetales. Sintomatología característica de los virus vegetales. Diagnosis de las virosis vegetales. Principales virosis vegetales. Viroides vegetales.

Actividad a desarrollar: Prácticas de laboratorio (Práctica 13): se reconocerán los síntomas originados por las principales virosis vegetales. Búsqueda de información: se propondrá la búsqueda de información y síntesis sobre diferentes virosis en la página Web de la Red temática española de mosca blanca y virosis. Debate: se propondrá la lectura y análisis de un artículo actual sobre un virus fitopatógeno de interés, con las mismas fuentes que en el tema 19.

Tema 22.- Agentes patógenos: nematodos: Definición. Morfología. Biología, reproducción y ciclo de desarrollo. Síntomas y daños producidos por nematodos. Principales grupos de nematodos fitoparásitos: formadores de nódulos en la raíz, formadores de quistes, del bulbo o del tallo, de la madera del pino y otros.

Actividad a desarrollar: Prácticas de laboratorio (Práctica 14): se extraerán nematodos de quiste y se observarán sus principales estructuras. Búsqueda de información: se propondrá la búsqueda de información y síntesis sobre diferentes enfermedades producidas por nematodos en la página Web de la American Phytopathological Society. Debate: se propondrá la lectura y análisis de un artículo actual sobre un nematodo fitopatógeno de interés, con las mismas fuentes que en el tema 19.

Tema 23.- Enfermedades abióticas: Efectos del ambiente en la producción de enfermedades no infecciosas o abióticas: Temperatura; Humedad; Viento; Luz; pH del suelo; Contaminación atmosférica; Nutrición de la planta huésped: carencias y toxicidades; Productos fitosanitarios.

Actividad a desarrollar: Salidas a campo: se observarán cultivos con diferentes síntomas originados por enfermedades abióticas.

\section{Bloque III: Control de plagas y enfermedades.}

Tema 24.- Métodos de control de plagas y enfermedades: Métodos de control de plagas y enfermedades Factores implicados en el control de plagas y enfermedades: política económica, ambientales, presencia /ausencia de enemigos naturales y otros. Métodos de control disponibles en la actualidad: legales, genéticos, culturales, físicos y mecánicos, químico, biológico e integrado. Elección del método óptimo en cada caso.

Actividad a desarrollar: Búsqueda de información: se propondrá al alumno la búsqueda y síntesis de información sobre diferentes organismos de cuarentena en la 
Web de la European and Mediterranean Plant Protection Organization. Seminarios: grupos de dos o tres alumnos prepararán una ponencia sobre plagas o enfermedades vegetales de interés en diferentes comunidades autónomas que luego será discutida por el resto de la clase. Se propondrá que la información de partida sea obtenida a partir de, entre otros, Boletines Fitosanitarios sobre plagas y enfermedades disponibles en la Web de la Junta de Castilla y León, Fichas de Plagas disponibles en la Web de la Generalitat de Cataluña, Hojas informativas monográficas sobre Protección Vegetal del Gobierno de Aragón u Hojas informativas del Instituto Técnico y de Gestión Agrícola de Navarra.

Tema 25.- Control químico: Denominaciones. Características: Composición y formulación; Presentación; Toxicidad; Residuos de plaguicidas; Almacenamiento, manipulación y mezcla de productos fitosanitarios; Etiquetaje, legislación y registro de productos fitosanitarios; Importancia de la elección del método de aplicación de productos fitosanitarios. Clasificación según: Agente sobre el que actúan; Grupo químico; Comportamiento en la planta; Especificidad; Modo de acción.

Actividad a desarrollar: Prácticas de laboratorio (Práctica 15): se enseñará a buscar la recomendación de control químico adecuada para diversas plagas en distintos cultivos, y se estudiarán las características de los formulados elegidos.

Tema 26.- Problemas derivados del uso de productos fitosanitarios: Aspectos generales. Problemas para la agricultura: Fitotoxicidad; Resistencia; Incremento de plagas inducido por plaguicidas; Eliminación de la fauna útil. Problemas para el medio ambiente: Fauna; Suelo; Agua. Problemas para el aplicador y el consumidor: Intoxicación; Límites máximos de residuos; Plazos de seguridad.

Actividad a desarrollar: Búsqueda de información: se propondrá al alumno completar la información de los vídeos proyectados en clase con la consulta de Liñán de (2013) y de diferentes Manuales de Aplicación de Plaguicidas (niveles básico y cualificado).

Tema 27.- Lucha biológica contra las plagas: Definiciones. Utilización de entomófagos: Depredadores; Parasitoides; Estrategias de control biológico; Métodos de evaluación de la eficacia de los enemigos naturales. Lucha microbiológica: Hongos entomopatógenos; Bacterias entomopatógenas; Virus entomopatógenos; Nematodos entomopatógenos.

Actividad a desarrollar: Lectura: se propondrá la lectura y síntesis de información disponible sobre control biológico de plagas en la Web de la Universidad de Almería. Búsqueda de información: se propondrá la búsqueda de información y síntesis sobre los efectos secundarios de los plaguicidas en los organismos beneficiosos disponibles en diferentes páginas Web como la de la empresa Biobest, la de la empresa Koppert y la de la Unidad de Entomología del Instituto Valenciano de Investigaciones Agrarias. Debate: se propondrá la lectura y análisis de un artículo actual sobre la lucha biológica contra las plagas. Dicho artículo procederá de una revista científica o de las actas de un congreso o reunión científica relacionados con este tema. 
Tema 28.- Lucha biológica contra las enfermedades: Lucha microbiológica. Mecanismos de actuación. Utilización práctica. Situación actual y problemas que presenta.

Actividad a desarrollar: Lectura: se propondrá la lectura y síntesis de información disponible sobre control biológico de enfermedades en la Web de la Universidad de Almería. Debate: se propondrá la lectura y análisis de un artículo actual sobre la lucha biológica contra las enfermedades, con las mismas fuentes que en el tema 27.

Tema 29.- Lucha biotécnica: Hormonas y reguladores del crecimiento. Plaguicidas de origen natural. Feromonas. Otros métodos atracticidas. Lucha autocida.

Actividad a desarrollar: Salidas a campo: se observarán diferentes métodos de lucha biotécnica.

Tema 30.- Protección Integrada contra plagas y enfermedades: Definiciones. Protección Integrada: Normativa y objetivos; Normas generales; Planes de actuación; Registro y certificación. Producción ecológica. Umbrales económicos de tratamiento.

Actividad a desarrollar: Búsqueda de información: se propondrá al alumno la búsqueda y síntesis de información en la Web sobre las Agrupaciones de Tratamientos Integrados en Agricultura (ATRIAS). Debate: los alumnos buscarán los reglamentos de Producción Integrada para los distintos cultivos en Castilla y León y otras comunidades.

Según todo lo expuesto, la planificación proyectada teniendo en cuenta las directrices recogidas en la normativa es de: (i) 60 horas de enseñanza presencial -30 clases magistrales participativas ( 23 horas), 15 prácticas de laboratorio ( 8 horas), 2 prácticas de campo (10 horas), varios seminarios según el número de alumnos (6 horas), 8 debates dirigidos (4 horas), tutorías (5 horas) y exámenes (4 horas)- y (ii) 90 horas de enseñanza no presencial -28 lecturas y búsquedas de información (25 horas), 1 trabajo académico que se expondrá en los seminarios ( 2 horas), 4 debates dirigidos ( 2 horas), 6 pruebas virtuales ( 6 horas), tutorías (5 horas) y el estudio autónomo (50 horas)-.

\section{Resultados y discusión}

La evaluación de la docencia se realiza en 3 ámbitos educativos: (i) el profesor -según el Programa Docentia (Universidad de León, 2010)-, (ii) el alumno -se presenta a continuación-, y (iii) la programación docente -a través de la consulta directa al final de cada unidad didáctica y de una encuesta al finalizar las actividades presenciales de la asignatura-.

Los criterios para la evaluación de los alumnos son:

Evaluación de los contenidos teóricos y aplicados que supondrá un $60 \%$ de la nota final: 
Exámenes escritos (50\%): 2 exámenes parciales $(2 \mathrm{~h})$ y 1 examen final $(1 \mathrm{~h})$ : preguntas de respuesta corta $(70 \%)$ y preguntas de respuesta larga $(30 \%)$.

Cuestionarios a través de la plataforma de campus virtual (50\%): 6 cuestionarios (6h): preguntas de elección múltiple o preguntas verdadero/falso.

Evaluación de las prácticas de laboratorio y campo que supondrá un $25 \%$ de la nota final:

Informe de actividades.

Cuestionarios (reconocimiento de insectos y síntomas originados por patógenos).

Evaluación de la participación activa en debates, seminarios y clases que supondrá el $10 \%$ de la nota final.

Evaluación de las lecturas y búsquedas de información que supondrá el 5\% de la nota final: síntesis, conclusiones y opinión.

\section{Conclusiones}

Se considera que la propuesta educativa expuesta fomenta el nuevo enfoque metodológico del sistema educativo basado en el "aprendizaje" gracias a la utilización de metodologías más activas, que conllevan a una mayor implicación y autonomía del estudiante, y a un nuevo papel del profesorado, como agente creador de entornos de aprendizaje que estimulen a los alumnos. Además, posibilita la adquisición de las competencias necesarias para el ejercicio de la actividad para la que habilitan los grados de los ámbitos agrarios en los que se imparte la asignatura.

La acogida por parte del estudiante de esta nueva metodología es en general positiva, si bien los alumnos más tímidos indican su inhibición ante la participación activa en actividades presenciales. Esto podría solventarse mediante la ayuda del profesor, así como mediante la expresión de su proceso de aprendizaje a través de las actividades no presenciales.

\section{Bibliografía}

BARBAGALLO, S.; CRAVEDI, P.; PASQUALINI, E.; PATTI, I. (2002). Pulgones de los principales cultivos frutales. Madrid: Mundi-Prensa.

BOE (2007). REAL DECRETO 1393/2007, de 29 de octubre, por el que se establece la ordenación de las enseñanzas universitarias oficiales. En: Boletín Oficial del Estado, no 209. Madrid: Ministerio de la Presidencia. http://www.boe.es/boe/ dias/2007/10/30/pdfs/A44037-44048.pdf. [1-07-2013]. 
BOE (2009). Orden CIN/323/2009, de 9 de febrero por la que se establecen los requisitos para la verificación de los títulos universitarios oficiales que habiliten para el ejercicio de la profesión de Ingeniero Técnico Agrícola. En: Boletín Oficial del Estado, $n^{\circ}$ 43. Madrid: Ministerio de la Presidencia. http://www.boe.es/boe/ dias/2009/02/19/pdfs/BOE-A-2009-2803.pdf. [5-08-2013].

LIÑÁN DE, C. (2013). Vademecum de productos fitosanitarios y nutricionales 2013. Madrid: Ed. Agrotécnicas S.L.

LLORENS, J.M.; GARRIDO, A. (1992). Homoptera (III): Moscas blancas y su control biológico. Alicante: Pisa ediciones.

UNIVERSIDAD DE LEÓN (2009). Memorias de verificación de los Grados en Ingeniería Agraria y del Medio Rural, Ingeniería Agroambiental, Ingeniería Agroalimentaria e Ingeniería Forestal y del Medio Natural. León: Escuela Superior y Técnica de Ingeniería Agraria, Universidad de León.

UNIVERSIDAD DE LEÓN (2010). Programa de apoyo a la evaluación de la actividad docente del profesorado de la ULE (Docentia): Modelo de evaluación de la actividad docente del profesorado de la Universidad de León. León: Oficina de Evaluación y Calidad, Universidad de León.

\section{La autora}

Alicia Lorenzana de la Varga es Doctora Ingeniero Agrónomo por la Universidad de León. Como personal del área de Producción Vegetal del Departamento de Ingeniería y Ciencias Agrarias de esta Universidad, desarrolla sus funciones docente, investigadora y de gestión en la Escuela Superior y Técnica de Ingeniería Agraria y es miembro del grupo de investigación "Ingeniería y Agricultura Sostenible", temática en la que se centran sus publicaciones. 